\title{
क्षे \\ Euclides e a geometria do raio visual
}

\section{Guilherme Rodrigues Neto}

Este ensaio introdutório faz uma breve apresentação do tratado de óptica atribuído a Euclides de Alexandria, inserindo-o no contexto das teorias sobre a visão formuladas pelas doutrinas filosóficas antigas. Ressalta-se o antagonismo entre a análise geométrica da visão, empreendida por Euclides, e as considerações filosóficas acerca dos processos físicos subjacentes à sensação visual. Pretende-se mostrar que o objeto da óptica euclidiana é a percepção visual daquilo que Aristóteles denomina "sensível comum".

O texto que a seguir publicamos é uma tradução do breve tratado de óptica atribuído ao famoso geômetra antigo Euclides de Alexandria. Escrito na primeira metade do século III a. C., o tratado de Euclides sobre a geometria da visão, um dos venturosos frutos da ciência helênica, é a primeira elaboração que possuímos em torno daquilo que hoje denominamos de "óptica geométrica". Todavia, diferentemente de Os elementos, sua obra mais conhecida e monumental, e cuja influência permaneceu presente até o final do século xix, a Óptica de Euclides certamente teve uma fortuna mais modesta.

Conhecida como Liber de visu - e, em alguns manuscritos medievais, como Liber de aspectibus -, a versão latina da óptica euclidiana foi bastante difundida no ocidente medieval. ${ }^{1}$ Em sua edição crítica do texto latino da Óptica, W. R. Theisen conseguiu anotar a existência de vinte e um manuscritos espalhados por toda a Europa, todos datados entre os séculos xiI e xVI (cf. Theisen, 1979, p. 54-9). A partir do início do século xvi e ao longo do século xvir, a Óptica de Euclides recebeu algumas poucas edições impressas, entre as quais temos a editio princeps de Jean Pena, publicada em Paris em 1557, com as versões grega e latina do tratado, e outras edições menores, incluindo traduções para o vernáculo - em italiano (1573), em espanhol (1585) e em francês (1663) (cf. Eecke, 1959, p. xxxvi-xlvii; Simon, 1988, p. 58-61). Entretanto, com a emergência da

1 A versão latina do tratado de Euclides, felizmente, é obra de tradução direta da versão grega original, diferentemente do tratado de óptica atribuído a Ptolomeu, cuja tradução latina é indireta, feita a partir de uma versão árabe do texto grego original, para sempre perdido (cf. Theisen, 1979, p. $5^{3}$; Smith, 1996, p. 7). 
técnica geométrica da figuração em perspectiva, cujas regras foram codificadas por Leon Battista Alberti em meados do século xv, e com a profunda reforma da ciência da óptica, iniciada no século xı por filósofos árabes e completada por Kepler no início do século XVII, a teoria euclidiana do "raio visual" tornou-se "falsa" e deixou de suscitar interesse científico, ou melhor, seu objeto, "o cone de raios visuais", como diz Gérard Simon, "deixou de existir em nossa cultura" (Simon, 1988, p. 11).

\section{Os ANTIGos E A VISÃo}

Os antigos tinham a sua disposição uma variedade de doutrinas filosóficas para explicar a natureza e a operação da visão. Pitágoras e Empédocles, Platão e Aristóteles, os atomistas e os estoicos, todos ofereceram diversas respostas sobre a questão particular acerca da sensação visual, e todas elas como subsidiárias em relação à questão geral em torno da natureza da sensação. Essas doutrinas filosóficas compartilhavam a ideia fundamental de que toda experiência sensível é o resultado de algum tipo de contato físico, ainda que mediado, entre o órgão sensorial e o objeto de sensação; sustentavam, pois, que a condição necessária para que ocorra uma sensação é a existência de alguma contiguidade entre os termos da sensação (cf. Smith, 1996, p. 21). Assim, a principal dificuldade concerne à explicação específica acerca da sensação visual, uma vez que é nesse campo sensorial que a separação, ou a não contiguidade, entre os termos da sensação torna-se mais manifesta e problemática. A fim de solucionar tal dificuldade, os antigos elaboraram diferentes teorias que tentavam explicar de que maneira a aparente ação a distância envolvida na sensação visual poderia ser reduzida a uma operação física que se realiza por contato. Três são as possibilidades de pensar isso: ou (i) alguma coisa que provém do exterior entra no órgão visual, ou (ii) alguma coisa que provém do próprio órgão sensorial (o olho) sai para alcançar seu objeto - ou para "coalescer" com algo que sai desse mesmo objeto -, ou (iii) nenhuma das duas alternativas anteriores, ou seja, nada entra e nada sai do órgão da sensação.

A primeira dessas alternativas foi proposta pela tradição do atomismo antigo, de Demócrito, Epicuro e Lucrécio, cuja doutrina postulou a existência de eidola, ou películas superfinas (superficiais) que são emitidas das superfícies dos corpos visíveis e que funcionam como réplicas disposicionais, como operadores visuais que tornam a visão possível ao realizar o requerido contato entre o órgão e a coisa que se vê. De acordo com a doutrina atomista, essa entidade mediadora da ação visual, assim como tudo o mais no mundo, é de natureza material - ou corporal - e, além disso, tais eidola devem ser extremamente tênues para que possam desempenhar suas funções, isto é, tais operadores visuais devem possuir uma natureza minimamente corporal, devem ser 
“superficiais", pois seus volumes devem possuir uma insensível espessura mínima para que sejam capazes de deslocar-se com insensível velocidade, atravessar corpos duros transparentes, não ser percebidos por outros sentidos etc. e, contudo, possam manter a configuração original da "réplica" e produzir, assim, uma "imagem", ou engendrar, pelo contato físico, a semelhança daquilo que se vê - sua figura e sua cor - no órgão recipiente e passivo da sensação visual. ${ }^{2}$

A segunda alternativa possível para a explicação da sensação visual foi elaborada no interior da tradição pitagórico - platônica. Segundo a doutrina de origem pitagórica, a visão é o resultado de alguma coisa que sai do olho - um "fogo ou fluxo visual" - e atinge "fisicamente" os objetos visuais, ou seja, os objetos visíveis serão vistos quando a emissão a partir do olho lhes "tocar". É como se, para ver, o olho, cuja natureza material é constituída pelo elemento fogo, devesse emitir sua própria luz, seu "fogo visual". Com isso, a condição necessária do contato na sensação é satisfeita - a sensação visual compartilha da natureza do tangível. Como diz Gérard Simon, a ideia de um "fogo visual", de uma emissão a partir do olho, "faz pensar em uma excrescência psíquica que sai de nosso olho como um pseudópode sensitivo" (Simon, 1988, p. 33). ${ }^{3}$

A doutrina visual de Platão é mais elaborada do que essa versão simplificada e requer, ainda, que essa emissão a partir do olho - essa "mão visual" - sofra aquilo que a tradição denominou de "coalescência" (synaugeia) com a luz do Sol (cf. Beare, 19o6, p. 45, nota 1). Com isso, Platão parece multiplicar as entidades, uma vez que sua doutrina requer, ademais da emissão a partir do olho, uma emissão de luz a partir do Sol. ${ }^{4}$

2 Sobre a natureza de tais eidola, Epicuro afirma: "Existem contornos ou películas que são da mesma forma que os corpos sólidos, mas de uma tenuidade que ultrapassa a de qualquer corpo visível. Pois não é impossível que se encontre no ar circundante combinações de materiais adaptados para expressar a concavidade e a tenuidade das superfícies e também as emanações que preservam o mesmo movimento e posição relativa que tinham nos corpos sólidos dos quais vieram. A essas películas damos o nome de 'imagens' [eidola]" (Epicuro apud Laertius, Livro x, $\S 46 ; 1925,2$, p. 575). Lucrécio elabora sua versão em verso da doutrina epicurista da sensação no quarto livro do De rerum natura. O caso de Demócrito é um pouco distinto, pois há indícios documentais de que compartilhava uma doutrina visual mais próxima à de Platão, uma teoria que admitia elementos extramissionistas. Sobre as ideias de Demócrito acerca da visão, cf. Beare, 1906, p. 23-37; Siegel, 1969; Baldes, 1975; Burkert, 1977. Sobre a doutrina epicurista da sensação visual, cf. Furley, 1987, p. 131-5; Simon, 1988, p. 36-9; Rudolph, 2011.

3 A doutrina estoica do pneuma visual insere-se nessa tradição. Sobre a teoria estoica da visão, cf. Lindberg, 1976, p. 9-11; Simon, 1988, p. 31-4; Løkke, 2008; Darrigol, 2012, p. 7-8.

4 Talvez não se trate propriamente de uma emissão a partir do Sol, mas simplesmente da presença da luz no ar ambiente. É difícil saber qual é a natureza da luz para Platão, se ela é substância - "um fogo", como para Empédocles - ou, então, uma qualidade dos corpos transparentes - como para Aristóteles. Platão parece mais interessado nos aspectos epistemológicos em torno da sensação do que em questões acerca da "física" subjacente à visão. Em todo caso, na doutrina visual de Platão, a luz aparece meramente como uma condição para a visão, em vez de ser, como diz Gérard Simon, "o protagonista principal de uma teoria da visão" (Simon, 1988, p. 25), o que só ocorrerá com as teorias ópticas de Alhazen e Kepler. As passagens mais importantes sobre o problema da visão em Platão encontram-se em Timeu, 45b-d e 67c-68c, e Teeteto, 156d-e. Sobre a "luz do Sol", cf. República, Livro vi, 507d-5o8c. Sobre a doutrina platônica da visão, cf. Beare, 1906, p. 42-56; Lindberg, 1976, p. 3-6; Simon, 1988, p. 25-36; Smith, 1996, p. 22-3. 
Assim, para Platão, a sensação visual parece ser o resultado de um certo tipo de interação entre duas "emissões" - uma eferente, ou a partir de dentro (extramissionista), e outra aferente, ou a partir de fora (intromissionista). 5 Entretanto, deixando de lado as possíveis e problemáticas interações físicas que devem ocorrer no mundo para que a visão possa ver, a ideia fundamental que a tradição pitagórico-platônica da teoria visual elaborou foi a noção de "raio visual". Como veremos, foi esse o conceito central que permitiu a Euclides empreender uma análise geométrica da visão. A assimilação teórica do "raio visual" a uma linha reta geométrica tornou possível uma geometrização da visão, o que permitiu à ciência helênica a elaboração, como diz Gérard Simon, de uma "analítica do visível” (cf. Simon, 1988, p. 74).

A terceira alternativa para explicar a experiência visual é aquela elaborada por Aristóteles no segundo livro do De anima. Ressaltando a função do meio transparente como "intermediário" da operação visual, a doutrina de Aristóteles parece livrar-se da aporia intromissionismo/extramissionismo. Em consonância com sua física, a visão não é o resultado de algum tipo de emissão, quer seja a partir do órgão sensorial, quer seja a partir das coisas visíveis. Com efeito, não existe qualquer tipo de emissão no mundo de Aristóteles, e também não há qualquer tipo de transporte ou troca material entre o órgão da visão e aquilo que se vê. O que há são somente atualizações de qualidades. Contudo, ainda que recuse qualquer tipo de emissão para explicar a visão, a doutrina de Aristóteles pode ser considerada como uma versão mais refinada de uma teoria visual intromissionista, uma vez que a sensação consiste, em geral, na "recepção de formas sensíveis sem a matéria" (De anima, II, 12, 424a17-18). Ou seja, a sensação visual, em sentido próprio e particular, consiste na recepção da "cor", a qualidade que constitui aquilo que Aristóteles denomina de "sensível próprio" da visão e que é sentida por meio de uma "forma sensível", a qual, de modo a afetar a faculdade da visão, deve ser transferida da superfície daquilo que se vê (“o visível”, to horaton), através de um meio diáfano cuja transparência deve estar presentemente atualizada, para o olho, que é o órgão próprio da visão. ${ }^{6}$

5 Essas categorias ("extramissionismo"/"intromissionismo") foram propostas por David Lindberg para classificar as diversas doutrinas visuais antigas de acordo com o sentido da radiação visual. Todavia, tal classificação não parece ser adequada para os casos de doutrinas "híbridas”, como as de Demócrito e de Platão. E a doutrina visual de Aristóteles, em que não há qualquer tipo de emissão, também não parece subsumir-se facilmente na categorização de Lindberg.

6 Como bem observa David Lindberg, “antes de Aristóteles, não temos qualquer discussão sistemática sobre a visão; de Platão e dos pré-socráticos, temos apenas citações fragmentárias e breves afirmações em obras dedicadas primeiramente a outros assuntos" (Lindberg, 1976, p. 6). O outro texto que compõe com o De anima o lugar clássico da elaboração - crítica e positiva - de Aristóteles sobre a visão, a luz e a cor é o pequeno tratado De sensu et sensibilibus . Nesse tratado, Aristóteles escreve o seguinte sobre a doutrina platônica do "raio visual": "Não é razoável, de modo geral, supor que a visão vê em virtude de algo que sai do olho e que poderia alcançar as estrelas, ou mesmo ir até certo ponto e aí coalescer, como dizem alguns. Seria melhor supor que tal coalescência ocorre no próprio elemento do 
É interessante notar que uma condição necessária para que a "forma sensível" da cor possa afetar o órgão visual é que o meio diáfano (o ar, a água, o vidro) deve estar atualmente transparente, isto é, o meio deve estar iluminado, ou seja, deve haver luz para que a cor seja vista. A transparência dos corpos diáfanos - e se vê através desses corpos - é uma qualidade que esses corpos possuem de modo potencial e que éatualiza$d a$ instantaneamente quando existe a presença de "fogo ou algo do tipo, como o corpo superior [o Sol]" (De anima, II, 7, 418b12-13). E a luz consiste precisamente nisso, na atualização ou atividade da qualidade da transparência, a qual é mantida em tal estado pela presença de uma substância capaz de engendrar tal alteração qualitativa no meio intermediário - ausente tal substância, o meio retorna instantaneamente a seu estado de transparência potencial, ou seja, a luz torna-se trevas. "Luz", diz Aristóteles, "é como que a cor do meio transparente", quando este está ativado ou atualizado pelo elemento fogo (De anima, II, 7, 418bı11).? Desse modo, para Aristóteles, assim como para Platão, a presença de "luz" é uma condição necessária para a visão. Contudo, Aristóteles, ou qualquer outro na Antiguidade, jamais pensou que a visão fosse o resultado da entrada da própria luz e de suas modificações ópticas (ou dióptricas) no interior do olho.

Diferentemente da doutrina platônica da visão, Aristóteles considera que o olho, que é o órgão próprio da visão, ao receber, ou assimilar, a "forma sensível da cor", a qual lhe é transferida a partir da superfície dos corpos através de um meio iluminado, é completamente passivo na relação visual, isto é, o órgão próprio da visão deve sofrer uma ação que provém do exterior. E a ação dessas “formas sensíveis" visuais deve engendrar - como efeito ou reação - algum tipo de alteração ou de mudança qualitativa no olho, alteração essa que define o próprio ato da visão. ${ }^{\mathbf{8}}$ Assim, sentir é ser "alterado", de algum modo, por "formas sensíveis", isto é, por "qualidades sensíveis".

olho. (...) Que sem luz a visão é impossível, já foi dito em outro lugar, mas, quer seja água ou ar o meio entre o olho e aquilo que é visto, a visão é causada por um processo [metaksy] nesse meio" (De sensu et sensibilibus, 4,38a25-4,38b2). Todavia, existem algumas breves passagens em outros textos de Aristóteles que estão em desacordo, pelo menos aparente, com a teoria exposta no De anima e no De sensu et sensibilibus. Em tais passagens, Aristóteles parece manifestar certo compromisso com a doutrina platônica do "raio visual" e contrariar, assim, a ideia de que a visão não se faz pelo caminho eferente do "raio visual ocular", mas pela via aferente da recepção da forma sensível. Em De caelo, em um contexto de discussão sobre a percepção do movimento dos corpos celestes, Aristóteles diz, de modo apa-

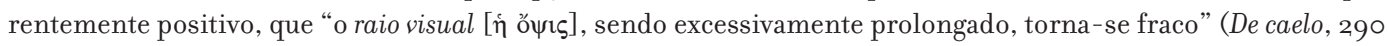
a17-18). Cf. também, por exemplo, Meteorologica, 37oa18-19, 373b-10, 374b11-15; De somniis, 459b24-46oa33. Sobre a doutrina aristotélica da sensação visual, cf. Beare, 1906, p. 56-92; Hamlyn, 1959; Sorabji, 1971; Lindberg, 1976, p. 6-9; Simon, 1988, p. 42-52; Zingano, 1998, p. 53-98; Polansky, 2007.

7 Vale ressaltar que, para Aristóteles, a luz não é uma substância, ou um corpo dotado de "movimento local”, mas uma qualidade de uma substância (ar, água, vidro), a saber, sua transparência, uma qualidade que se manisfesta de modo instantâneo e ubíquo (cf. De anima, II, 7, 418b20-5; De sensu et sensibilibus, 6, 445a26-446b2).

8 Sobre a problemática natureza de tal "alteração" (ou immutatio) que se produz no órgão visual pela ação da "forma sensível”, cf. Sorabji (1974) e Burnyeat (2002), os quais sustentam interpretações antagônicas, conhecidas na literatura como "fisicalista" e "espiritualista" (ou "mentalista"), respectivamente. 
Com tudo isso, o processo inteiro da sensação visual está completo - tudo ocorre sem intervalo de contiguidade: corpo visível/cor (forma visível)/meio transparente/cor (forma visível)/olho.

Aristóteles pensa que a sensação da cor - que é própria à visão e produzida de modo imediato pela recepção ou assimilação da forma sensível - deve ser sempre verídica, ou seja, que ela não é falível, não está sujeita a erro, que não é possível enganar-se em relação à própria forma sensível recebida. 9 Todavia, o olho não sente somente variações de cor. Ademais da cor, que é a qualidade sensível que Aristóteles denomina de "sensível próprio" da visão, o olho também "percebe" os chamados "sensíveis comuns", a saber, "o movimento, o repouso, o número, a figura e a magnitude" (cf. De anima, II, 6). Diferentemente das qualidades sensíveis próprias a cada um dos cinco sentidos, esses modos ou disposições não são percebidos somente por um único órgão sensorial especial ou por meio de uma "forma sensível" própria e particular antes, eles são "percebidos" por aquilo que o aristotelismo escolástico viria posteriormente a designar de sensus communis (cf. Des Chene, 2000, p. 28). Além disso, e é o que importa ressaltar, Aristóteles considera que a percepção desses “sensíveis comuns”, diferentemente da sensação dos “sensíveis próprios”, não é infalível, ou seja, as "percepções visuais" acerca do tamanho, da figura, da distância e do movimento, embora percebidas "por si mesmas" pelo olho, não estão, como a "sensação visual” da cor, livres de erro, mas são sempre passíveis de erro, isto é, os objetos sensoriais comuns, diferentemente dos objetos sensoriais próprios, podem produzir sensações "falsas". ${ }^{10}$

9 Aristóteles é bastante obscuro em fornecer as razões de por que as sensações próprias a cada sentido especial devem ser sempre verdadeiras. A infalibilidade das sensações concernentes aos "sensíveis próprios" deve ser atribuída, talvez, ao fato de que tais sensações constituem-se como efeitos necessários de causas formais - das "formas sensíveis" -, e que, por isso, elas devem ser genuínas, infalíveis. Assim, por exemplo, uma vez que a "forma sensível" da cor branca não pode engendrar outra coisa no órgão da visão senão a própria cor branca, a sensação da cor branca jamais pode, por isso, equivocar-se quanto a si mesma.

10 Aristóteles tampouco parece fornecer uma explicação suficientemente clara e satisfatória acerca da falibilidade da percepção dos "sensíveis comuns", ou de por que esse tipo de "objeto" sensorial comum pode engendrar sensações não verídicas. Diz Aristóteles: “[...] a percepção dos objetos sensoriais próprios é verdadeira ou admite minimamente o falso, mas, em segundo lugar, há a percepção incidental [ou concomitante] daquilo que é incidental [ou concomitante] aos sensíveis, e neste caso já é possível o falso; pois que é branco, não se comete erro, mas pode-se errar quanto ao branco ser isso ou aquilo. Em terceiro lugar, há a percepção dos sensíveis comuns que acompanham os incidentais [ou concomitantes] em que ocorrem os sensíveis próprios, por exemplo, o movimento e a magnitude, a respeito dos quais já é possível enganar-se segundo a sensação" (De anima, ıII, 3, 428bı-24; grifo meu). Ou seja, os sensíveis comuns sempre "acompanham", necessariamente, os “sensíveis próprios”. Assim, quando vejo a cor branca, sempre a vejo, necessariamente, como figurada e localizada, e também sempre em deslocamento ou em repouso. Todavia, é acidental que a cor apareça com uma determinada figuração particular, isto é, como quadrada, como triangular ou como circular, e também que apareça em uma determinada região e com um determinado movimento. Pode-se dizer que a ideia de "sensíveis próprios" (ou "sensíveis simples") é uma abstração que resulta da própria análise que Aristóteles faz da experiência sensorial. Com efeito, a visão nunca apreende isoladamente seu 
Portanto, quando existe erro na sensação visual, tal engano deve situar-se, pensa Aristóteles, não na própria sensação da cor daquilo que é visto, mas na percepção do tamanho, da figura, da distância e do movimento daquilo que é visto, percepções essas que sempre "acompanham" as "sensações próprias" (cf. De anima, III, 3, 4228b17-24). Assim, em sentido estrito, não existe erro na própria sensação especial, esta não poderia equivocar-se a respeito de si mesma, pelo menos quando as condições naturais são satisfeitas. ${ }^{11}$ Como veremos adiante, o objetivo da ciência euclidiana da óptica é justamente a "descrição" geométrica da aparência visual desses "sensíveis comuns". O que o geômetra antigo propõe-se a fazer é explicar ${ }^{\mathbf{1 2}}$ a aparência visual do tamanho, da figura e do movimento daquilo que é visto, ou daquilo que aparece aos olhos.

Essas são, em resumo, as principais ideias filosóficas que sabemos que os antigos elaboraram e de que dispunham para entender o que é a visão e de que maneira ela se faz. Todas essas doutrinas filosóficas centravam sua atenção nos processos físicos subjacentes à experiência visual, todas elas faziam diversas considerações a respeito da natureza do mundo e também a respeito da natureza do próprio órgão sensorial da visão - o que influenciou a tradição médica e suas considerações acerca da estrutura anatômica e das afecções do olho (cf. Tossato, 2005). O que essas diferentes doutrinas filosóficas sobre a visão pretendiam fornecer era uma teoria física da visão, isto é, uma explicação teórica dos elementos e processos físicos envolvidos no ato de ver.

Todavia, tal saber teórico não era capaz de informar, ou de instruir, algum interesse relacionado com problemas mais práticos, isto é, seu objetivo era o de conhecer e não o de fazer algo. Com efeito, as antigas teorias filosóficas acerca da visão não ense-

sensível próprio (a cor), mas compõe sempre uma experiência sensorial complexa, associada que está a seus acompanhantes "comuns". Ou seja, todas as sensações visuais são sempre complexas, porque a cor está sempre acompanhada de suas determinações espaciais. Assim, tudo aquilo que é ou se apresenta como colorido deve, necessariamente, ser ou se apresentar de determinada figuração, com certo tamanho, com determinado movimento, ou em repouso, e também como contínuo ou como descontínuo (em relação à percepção do "número"). Portanto, uma vez que toda sensação visual é, por si mesma, complexa, tem-se que a sensação é capaz de falhar no campo de seus "sensíveis comuns". Em De anima, III, 6, Aristóteles diz - referindo-se todavia ao pensamento e não à sensação que "o falso [quando houver] está sempre na composição" (4,3ob1-2). Sobre a distinção entre "sensíveis próprios" e "sensíveis comuns", cf. De anima, II, 6, 418a14-16; III, 3, 428b18-28; Metafísica, Iv, 5, 1010b2-3. Em De sensu, Aristóteles acrescenta à lista dos "sensíveis comuns" a "aspereza e a lisura" (cf. De sensu et sensibilibus, 4, 44,2b5-10). Sobre a questão da falibilidade das sensações dos sensibilia communis, cf. Hamlyn, 1959, p. 11-3; Block, 1961; Krips, 1980; Gaukroger, 1981; Polansky, 2007, p. 369-77, 418-20).

11 De acordo com a doutrina de Aristóteles, uma sensação visual "normal” deve satisfazer algumas condições: a presença externa de um objeto colorido, luz (isto é, um meio atualmente transparente entre o olho e o objeto), alguma distância entre o órgão sensorial e o objeto, uma constituição natural ou eficaz do órgão sensorial. Se todas essas condições forem satisfeitas, a sensação visual será “naturalmente” verídica, isenta de erro.

12 Não apenas fornecer uma explicação teórica, mas, sobretudo, informar práticas e técnicas relacionadas com a visualidade - no campo das artes figurativas, da cenografia, da arquitetura e, também, das observações dos astrônomos. 
javam a solução de qualquer problema prático concernente à visão, mas meramente ofereciam, por assim dizer, uma visão ou uma imagem teórica da experiência visual. Em contraposição, a análise geométrica que Euclides faz da experiência visual constitui uma ciência da perspectiva que parece ensejar um saber prático, uma vez que ela fornece recursos - e talvez esse seja seu aspecto mais interessante - para a solução de problemas no campo da altimetria, da cenografia, da arquitetura, da escultura e da figuração (cf. Panofsky, 1993 [1927], p. 78-9; Simon, 1988, $7^{3-6 ;}$;oo3, p. 50-3). E isso certamente conta como uma vantagem da perspectiva euclidiana em relação às teorias físicas sobre a visão formuladas pelas doutrinas filosóficas antigas.

\section{A ANÁLISE GEOMÉTRICA DA VISÃo}

Diferentemente das análises filosóficas e de suas suposições físicas sobre a natureza da visão, as quais eram isentas de qualquer consideração geométrica, a teoria euclidiana da visão estrutura-se como uma geometria e, à primeira vista, parece desprovida de qualquer consideração física acerca da operação da visão. Na análise geométrica que Euclides elabora em torno da experiência visual, os aspectos físicos que envolvem o ato da visão parecem ausentes. ${ }^{\mathbf{3}}$ Assim, a cor, a luz ou o transparente, a "forma sensível", o trânsito de eidola ou de imagens, a "coalescência" entre o raio visual ocular e a luz solar, o pneuma visual, a natureza do olho e a estrutura física dos órgãos sensoriais envolvidos na visão, todas essas noções estão excluídas da óptica de Euclides, nenhuma função visual lhes é atribuída - essas entidades não poderiam ser geometricamente analisáveis. ${ }^{\mathbf{1 4}}$ Como diz Gérard Simon, "Euclides precisava apenas de pontos, linhas retas e ângulos: todas as suas demonstrações são realizadas em preto e branco, ou segundo os traços monocromáticos do geômetra" (Simon, 1988, p. 64).

Desse modo, com a eliminação da consideração física acerca da natureza da visão e com a consequente redução analítica da experiência visual a uma consideração geométrica acerca das relações métricas e angulares entre os raios visuais (ou sua abertura angular) e as "magnitudes" interceptadas pela radiação ocular, a teoria óptica de Euclides aparece como que vazia de ontologia. Todavia, como bem observa David C. Lindberg, isso não deve ser tomado como totalmente correto, uma vez que a análise

13 Há uma famosa passagem da Física em que Aristóteles, ao elaborar sua distinção entre física e matemática, situa a ciência da óptica como uma ciência "subordinada" à matemática: “[...] a geometria estuda a linha natural, mas não enquanto natural, ao passo que a óptica estuda a linha matemática, não enquanto matemática, mas enquanto linha natural" (Física, II, 2, 194a10-11).

14. Aluz, a cor e as estruturas ópticas do olho serão geometricamente analisáveis somente a partir da óptica moderna de Kepler, Descartes e Newton. 
geométrica da visão elaborada por Euclides certamente supõe uma teoria física mínima acerca da operação da visão (cf. Lindberg, 1976, p. 13-4). Com efeito, há uma série de suposições "físicas", todas enunciadas por Euclides no início de sua composição, que está subjacente a sua análise geométrica e que constitui o núcleo da teoria euclidiana da visão, a saber, (i) que a visão se faz por extromissão a partir do olho de (ii) "raios visuais" - entidades discretas e divergentes, que operam como "agentes físicos" da visão -, os quais (iii) tocam, de modo descontínuo, a superfície de "magnitudes visíveis" e que (iv) quanto maior a quantidade de "raios visuais" (ou quanto maior o número de "ângulos de visão"), maior a "distinção" (acribeia) da aparência visual, ou seja, que a sensibilidade visual varia de acordo com a magnitude do ângulo visual. O "raio visual", como diz Gérard Simon, não é meramente "uma abstração [geométrica], mas uma realidade [física]; uma realidade que se tornou literalmente inconcebível para nós, uma vez que se trata de uma projeção, ao mesmo tempo, material e psíquica - constituída de elementos, ar ou fogo, análogos àqueles da matéria inerte, e sendo, ainda assim, vetor de sensibilidade" (Simon, 2003, p. 22; grifos do autor).

A ideia de que o olho é um emissor de "raios visuais" - e que, portanto, ele é um participante ativo do processo visual - situa a elaboração de Euclides na tradição platônica da teoria da visão e sugere um vínculo de parentesco com a doutrina estoica do pneuma visual. ${ }^{\mathbf{1 5}}$ Contudo, na análise de Euclides, o olho é reduzido a um ponto geométrico que se localiza no vértice do cone visual, ele é meramente o ponto geométrico da origem do cone de raios visuais discretos e divergentes. ${ }^{\mathbf{1 6}}$ Não há referência alguma a partes anatômicas do órgão visual, tampouco a partes do cérebro ou a "espíritos animais". ${ }^{17}$ A operação do olho é reduzida simplesmente a uma posição, a qual está ora parada diante de uma magnitude, ora em movimento, e a partir da qual a distribuição angular dos "raios visuais" determina a percepção visual do tamanho, da figura e do movimento "daquilo que é visto" (to horomenon), isto é, sua "aparência" visual.

A análise geométrica que Euclides faz da visão funda-se na redução da visão a um modelo geométrico, no qual o campo visual é tomado como uma coleção, ou agregado, de "raios visuais" concebidos como linhas retas geométricas discretas e divergentes, as quais aparecem como o último termo da análise. Essa coleção de linhas retas "visuais" divergentes, em cuja origem encontra-se o olho, assume a forma estereomé-

15 Euclides se compromete com alguma doutrina filosófica da visão? A opinião corrente na historiografia é a de que a análise que Euclides faz da visão situa-se no interior da tradição pitagórico-platônica (cf. Eecke, 1959, p. xiii-xiv; Lindberg, 1976, p. 15; Simon, 1988, p. 25-35; 2003, p. 18; Darrigol, 2012, p. 9).

16 Euclides situa o olho no ápice do cone visual, mas não esclarece onde exatamente tal ponto deve ser situado, se na superfície exterior, no centro do olho (no cristalino) ou na parte posterior do olho (na retina).

${ }_{17}$ Em quatro proposições de sua Óptica (Prop. 25-28), Euclides faz referências à distância "anatômica" entre os dois olhos, ou à linha reta que une os dois olhos - uma magnitude certamente geométrica. 
trica de um cone geométrico, conhecido na tradição como "cone visual”, em cuja base encontra-se a figura daquilo que é visto, isto é, a superfície interceptada pelo feixe divergente de linhas retas visuais - entidades estas que possuem uma natureza híbrida, geométrico-sensível. Esse modelo geométrico da visão, o produto da análise operada por Euclides, estabelece, pois, uma demarcação do campo da ciência da óptica ao constituí-la como uma disciplina cujo objeto é a descrição geométrica da distribuição angular desses raios visuais. A suposição fundamental que permite geometrizar o olhar é, então, a de que a visão é definida por um "cone de raios visuais", isto é, uma "figura geométrica" constituída por uma coleção de "linhas retas" divergentes, uma figura que tem como sua base aquilo que é visto e como seu vértice o olho, ou a origem da emissão ocular. Assim, o geômetra confere ao olhar a forma de um cone geométrico projetado a partir do olho e, olhando com sua ciência esse olhar, ele deduz, ou deriva, um conjunto de relações geométricas (angulares) entre o olho e aquilo que aparece. O que aparece ao olho é determinado pelo geômetra como uma função das propriedades e relações geométricas que são derivadas dessa construção, a qual, ao reduzir o cone visual a uma projeção plana que resulta em triângulos definidos por um vértice situado no olho e por dois raios visuais que unem as extremidades daquilo que é visto, permite "calcular" a "aparência" do tamanho, da figura e do movimento daquilo que é visto.

Essa construção da estrutura geométrica do "cone visual" é delineada nas três primeiras "suposições" da Óptica, nas quais Euclides postula: (i) a retilineidade dos "raios visuais", 18 (ii) o "cone visual" constituído pela divergência desses raios visuais discretos e (iii) a condição geral da visibilidade, a saber, que, para ser visto, algo deve ser interceptado pelo radiação ocular. Lê-se:

\footnotetext{
18 Na primeira "definição" de sua Óptica, em que Euclides estabelece, ou postula, a retilineidade dos "raios visuais", de modo algum trata-se da retilineidade de "raios de luz". Existem inúmeros exemplos de considerações equivocadas na recente historiografia da ciência que afirmam que Euclides "demonstrou a retilineidade do raio de luz". Tais afirmações incorrem em dois equívocos, pois Euclides não demonstrou a retilineidade, uma vez que isso não é demonstrado, mas assumido como uma suposição, e tampouco se trata de raios de "luz", mas de "linhas retas visuais". Na proposição 18 da Óptica, existe uma referência a um "raio de Sol”, o qual é empregado no cálculo para a solução de um problema de altimetria. Todavia, tal entidade não possui qualquer função visual. Como bem observa Gérard Simon, na óptica antiga, a luz jamais aparece como "protagonista” do processo visual (cf. Simon, 1988, p. 11, 22-25). Com efeito, a óptica antiga não se constituiu como uma "física da luz", mas em uma "geometria da visão", e a noção de "raio de luz", tal como delineada na óptica moderna, jamais manifestou-se na ciência antiga. Ainda que possa existir, do ponto de vista geométrico, uma correspondência "exata", ou uma "equivalência conceitual", entre essas duas noções - "raios visuais" e "raios luminosos" -, ou ainda que o sentido (eferente ou aferente) da radiação possa ser abstraído, pois o que se considera são apenas linhas retas geométricas e não seria relevante, para o geômetra, de qual extremidade da linha reta visual provém a ação física da visão, mesmo assim trata-se de dois “mundos conceituais" totalmente distintos, os quais conduzem a questões bastante diversas (cf. Simon, 2003, p. 20).
} 
Definições:

1 Seja suposto que linhas retas traçadas a partir do olho atravessam uma distância de grande magnitude.

${ }_{2}$ E que a figura contida pelos raios visuais é um cone, cujo vértice encontra-se no olho e sua base nos limites daquilo que é visto.

$3 \mathrm{E}$ que aquilo sobre o qual os raios visuais incidem é visto e aquilo sobre o qual os raios visuais não incidem não é visto.

A essas “definições”, Euclides acrescenta mais quatro suposições que conferem, por assim dizer, um conteúdo sensível ao corpo geométrico da visão e que determinam a escolha de uma perspectiva óptica baseada na abertura angular. Euclides postula: (iv) que o tamanho aparente daquilo que é visto é diretamente proporcional à distância angular que separa os dois raios visuais que incidem em cada uma das extremidades daquilo que é visto, (v) que a posição daquilo que é visto é determinada pela distribuição dos raios visuais no interior do "cone visual" e (vi) que existe uma variação da acuidade visual, a saber, que algo é visto "mais distintamente" quanto maior o número de "raios visuais" o interceptarem. Lê-se:

4. E que, a partir de um ângulo maior, aquilo que é visto aparece maior, a partir de um menor, menor, e a partir de ângulos de visão iguais, igual.

5 E que, a partir de raios visuais mais altos, aquilo que é visto aparece mais alto, a partir de mais baixos, mais baixo.

6 E, similarmente, que, a partir de raios visuais mais à direita, aquilo que é visto aparece mais à direita, a partir de raios visuais mais à esquerda, mais à esquerda. 7 Enfim que, a partir de um maior número de ângulos, aquilo que é visto aparece mais distintamente.

Uma característica do cone visual euclidiano é sua discrição, ou seja, ele é composto por uma coleção de raios visuais concebidos como linhas retas geométricas discretas, isto é, como magnitudes que possuem somente comprimento e cuja largura é como um ponto, uma magnitude que não tem partes, que não pode ser dividida. ${ }^{\mathbf{9}}$ Assim, a radiação visual é concebida por Euclides como um feixe que intercepta seus objetos visuais de modo descontínuo, deixando intervalos "vazios" na superfície des-

19 Na Óptica de Ptolomeu, diferentemente da concepção de Euclides sobre o cone visual discreto (composto de linhas retas discretas), encontra-se uma concepção "continuísta" da radiação ocular, ou seja, os "raios visuais" são tomados meramente como uma "abstração" geométrica, sem realidade física efetiva, e, assim, o cone visual não é concebido como um agregado de linhas retas, mas como um corpo contínuo (cf. Lindberg, 1976, p. 16; Simon, 1988, p. 65-6; Smith, 1996, p. 23; Darrigol, 2012, p. 12). 
ses objetos, uma vez que tais intervalos seriam menores do que o arco subjacente ao "ângulo de visão mínimo". Por conta de sua descontinuidade, existem regiões de insensibilidade na base do cone visual e, por causa disso, tem-se a impossibilidade de perceber "simultaneamente" todas as partes daquilo que é visto, o que é "demonstrado" por Euclides no primeiro teorema de sua Óptica. Essa é uma característica física da descontinuidade da sensibilidade visual que decorre da própria análise geométrica que Euclides faz da visão.

A natureza física discreta do cone euclidiano fornece, assim, uma explicação para o limiar de visibilidade relacionado com a distância, ou seja, o cone entendido como coleção discreta de linhas retas "visuais" permite um entendimento do fato de que, para toda magnitude visível, qualquer que seja seu tamanho, existe uma determinada distância em relação ao olho a partir da qual a magnitude deixa de ser visível. Isso ocorre quando seu tamanho, devido à distância em que a magnitude encontra-se do olho, torna-se menor do que a corda que subentende o "ângulo de visão mínimo". Assim, uma vez que a magnitude deixa de ser interceptada pelos raios visuais, pois nesse caso estes passam a seu largo, ela deixa então de ser vista.

Outra consequência curiosa da natureza discreta do cone visual é o teorema enunciado por Euclides na nona proposição, em que se afirma que "magnitudes retangulares, distantemente vistas, aparecem arredondadas". Ou seja, do mesmo modo que no segundo teorema, devido à divergência dos raios visuais, o tamanho das regiões angulares que contornam a magnitude retangular torna-se menor do que o "ângulo de visão mínimo" e, por isso, a magnitude deixa de ser vista como retangular. É interessante notar que esse nono teorema da Óptica pode ser tomado como uma resposta a um dos argumentos que os céticos antigos elaboraram para fortalecer a suspensão do juízo acerca da verdade das aparências sensíveis. A objeção da torre quadrada - a qual, vista distantemente, aparece redonda - pertence ao grupo de argumentos céticos que Sexto Empírico registra no "argumento das posições, distâncias e localizações”, também conhecido como o "quinto tropo de Enesidemo" (cf. HP, I, 118-119). A ciência de Euclides parece fornecer uma resposta a tal desafio.

\section{A perspectiva do ÂNGUlo VISUAL}

Na quarta "definição" da Óptica, supõe-se que, "a partir de um ângulo maior, aquilo que é visto aparece maior (...)". Ou seja, a relação angular entre os raios visuais emitidos pelo olho e os diversos pontos dos objetos em que tais raios incidem define, na perspectiva de Euclides, o tamanho aparente que uma magnitude manifesta aos olhos. Isto é, postula-se que o tamanho aparente da magnitude vista é diretamente propor- 
cional ao tamanho da abertura do ângulo visual. Essa suposição assume, ao longo do tratado de Euclides, uma centralidade operativa no curso da maioria de suas demonstrações e expressa a "escolha" que funda a chamada "perspectiva natural dos antigos".

Assim, no curso de suas demonstrações de óptica, sempre que se põe a questão sobre o tamanho aparente daquilo que é visto, o objetivo de Euclides é o de reduzir o problema a uma relação de comparação entre ângulos, sempre recorrendo a teoremas já demonstrados em Os elementos. Desse modo, ao descobrir que um ângulo visual é maior do que outro - ou que possui determinada relação de tamanho com outro ângulo visual -, conclui-se que aquilo que é visto sob o primeiro ângulo é maior do que - ou que possui uma determinada relação de tamanho com - aquilo que é visto sob o segundo ângulo, uma vez que se tem como premissa fundamental que o tamanho aparente daquilo que é visto é diretamente proporcional ao tamanho do ângulo visual. Ou seja, quanto maior o ângulo de visão, tanto maior o tamanho aparente do objeto visível, ou da "magnitude vista", para usar o vocabulário de Euclides.

Em sua oitava proposição, Euclides extrai uma consequência negativa da suposição que estabelece uma relação direta entre a magnitude visível e o ângulo de visão que a captura, a saber, que o tamanho aparente daquilo que é visto não é proporcional (na razão inversa) à sua distância, ou afastamento em relação ao olho. Assim, ao supor uma relação direta de proporcionalidade entre tamanho aparente e ângulo visual, devese necessariamente negar a relação "alternativa" entre tamanho aparente e distância, uma vez que tais relações não são mutuamente compatíveis, isto é, uma vez que o tamanho aparente daquilo que se vê é diretamente proporcional à abertura do ângulo visual, então tal tamanho não pode ter alguma determinada relação de proporcionalidade com a distância ocular, ou com a extensão do raio visual, ainda que isso pareça ser o caso.

De acordo com a clássica interpretação de Erwin Panofsky, apresentada em seu notável ensaio de 1927, A perspectiva como forma simbólica, o "oitavo teorema" da Óptica de Euclides define a escolha fundamental da "perspectiva antiga", caracterizada como "perspectiva natural”, e está em "contradição" com a "perspectiva renascentista”, caracterizada como "artificial" e cujas regras foram codificadas por Leon B. Albeti, em seu De pictura (Da pintura), de 1435-1436 (cf. Panofsky, 1993 [1927], p. 36-8). Enquanto a perspectiva antiga, ou perspectiva naturalis, funda-se na suposição de uma relação direta de proporcionalidade entre o ângulo visual e o tamanho da "magnitude vista" e, assim, por consequência, recusa a relação de proporcionalidade entre o tamanho aparente e a distância, a perspectiva renascentista, ou perspectiva artificialis, por sua vez, assume como princípio precisamente essa relação entre distância e tamanho, exatamente o que é refutado nesta oitava proposição. Segundo Panofsky, tal antagonismo reside no fato de que o objetivo da perspectiva antiga era o de formular as "leis da visão natural", enquanto que a perspectiva renascentista pretendia estabelecer uma técni- 
ca, ou um método de figuração (cf. Panofsky, 1993 [1927], p. 37). A figura abaixo ilustra a discrepância entre a perspectiva antiga (natural, angular, curvilínea) e a perspectiva renascentista (artificial, linear, retilínea).

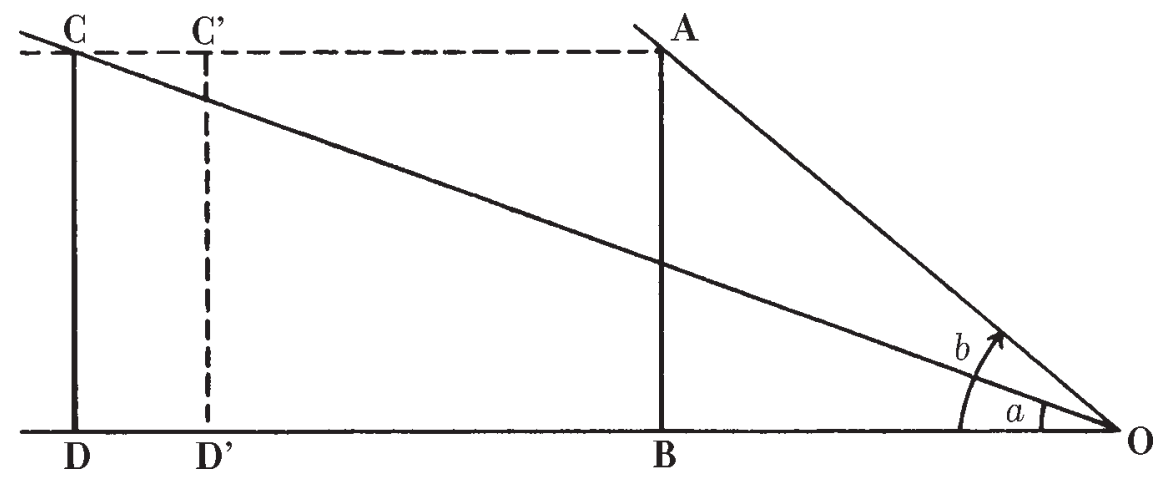

Figura 1. Segundo a perspectiva angular dos antigos, para dois ângulos, dos quais um é o dobro do outro $(b=\mathbf{2} \times a)$, a magnitude $\mathbf{A B}$ aparece diminuída na razão da metade quando posta em $\mathrm{CD}$, estando o olho em 0 . Por sua vez, segundo a perspectiva linear renascentista, cuja suposição fundamental é a da razão inversa entre tamanho aparente e distância, a posição "correta" em que a magnitude $A B$ aparece reduzida à metade, estando o olho em $\mathrm{O}$, deve ser em C'D' (pois OD' = $2 \times 0 B$ ), e não em CD (cf. Panofsky, 1993 [1927], p. 38; Simon, 1988, p. 67; 2003, p. 23).

Panofsky observa que, durante o Renascimento, com a emergência do sistema linear de representação espacial, o teorema do ângulo visual sofreu uma radical metamorfose, chegando mesmo a ser eliminado em algumas edições renascentistas da Óptica de Euclides. A “contradição” entre os dois sistemas de perspectiva tornar-se-ia cada vez mais evidente. Diz Panofsky:

Não será acidental que deparemos com paráfrases, com traduções até, de Euclides, feitas durante o Renascimento, nas quais seu oitavo teorema foi suprimido por inteiro ou submetido a tais 'correções' que o sentido original se perdeu. Sem dúvida que se fez sentir a contradição entre a perspectiva naturalis ou communis, defendida por Euclides, e a perspectiva artificialis, que então se desenvolvera. A primeira mais não procurou do que a formulação matemática das leis da visão natural, ligando, assim, a grandeza aparente ao ângulo de visão. Contrariamente a ela, a segunda tentou estabelecer um método que se provasse útil na representação de imagens em superfícies bidimensionais. Essa contradição só poderia ser resolvida com a rejeição do axioma dos ângulos (1993 [1927], p. 37). 
Todavia, qual era o objetivo da ciência de Euclides? A óptica euclidiana constituia-se como uma teoria da visão natural ou como um conjunto de soluções a problemas práticos de perspectiva, tal como uma técnica de figuração? Difícil dizer, mas talvez ela tenha servido, conjuntamente, a esses dois propósitos. Segundo Gérard Simon, em tal ambivalência reside a "equivocidade capital" da óptica de Euclides, "em nenhum momento do tratado faz-se a distinção entre as regras de perspectiva e as leis da visão" (Simon, 2003, p. 24; cf. Simon, 1988, p. 63-72). Com efeito, embora o objetivo mais evidente da Óptica seja a elaboração de uma teoria (geometricamente estruturada) da "visão natural", fundada no postulado do ângulo visual, a análise geométrica de Euclides também parece fornecer lições aos artistas de sua época.

Assim, por exemplo, nas proposições 37 a 4, a ciência de Euclides apresenta o que pode ser denominado de uma "teoria dos lugares ópticos", ou seja, procura-se determinar - tanto para os casos em que o olho está parado, enquanto a magnitude vista desloca-se com certo movimento, quanto para os casos em que a magnitude encontrase parada, enquanto o olho desloca-se com certo movimento - a existência de "lugares geométricos" a partir dos quais aquilo que é visto aparecerá sempre igual (do mesmo tamanho), ou algumas vezes igual e outras vezes desigual, ou ainda aparecerá na razão da metade, da terça parte ou em qualquer razão que se queira encontrar. Desse modo, Euclides constrói diversos "lugares geométricos" que indicam determinadas posições em que o olho deve ser posto, ou situado, para que a "magnitude vista" mantenha seu tamanho aparente - tais "lugares" podem ser definidos por pontos geométricos, nos casos em que o olho permanece parado, e também por linhas retas ou curvas, nos casos em que o olho é movido sobre uma linha reta ou sobre um segmento de círculo. É bastante provável que esse conjunto de teoremas seja responsivo a questões e problemas de natureza técnica, ou que elabore questões que pertencem mais ao campo da perspectiva artificial (isto é, como técnica de figuração) do que ao campo da óptica ou perspectiva natural (isto é, como teoria da visão), e que possua, pois, ampla aplicação em cenografia, arquitetura, escultura e pintura (cf. Panofsky, 1993, p. 78-81; Simon, 1988, p. $73-5$ ). Como salienta Gérard Simon, os problemas atacados por esse conjunto de teoremas de óptica têm a característica comum de "não contribuírem para a análise da visão propriamente dita", mas talvez atendam a uma demanda técnica e forneçam "aos artistas regras matemáticas para calcular correções apropriadas" - ou compensações de perspectiva - "nas proporções de suas obras monumentais" (Simon, 1988, p. 74). 


\section{A óPTICA GOMO GIÊNCIA DA APARÊNCIA DOS "SENSÍVEIS GOMUNS"}

Uma vez que a percepção dos "sensíveis comuns", como ensinava Aristóteles, não possui o mesmo estatuto epistemológico que a sensação dos "sensíveis próprios", sendo sempre sujeita a erro, então a ciência euclidiana da óptica pode ser considerada como um tipo de antídoto racional aos enganos que se produzem na apreensão visual desses "sensíveis comuns", ou da distância, do tamanho, da figura e do movimento de "magnitudes visíveis". A óptica de Euclides parece constituir-se, pois, como uma "ciência das aparências" desses "sensíveis comuns", ou seja, sua geometria da visão permite esclarecer e controlar, por assim dizer, certos enganos sensoriais envolvidos na percepção visual dessas configurações visíveis, permite "prever" racionalmente a aparência que o cone de raios visuais estampa sobre aquilo que é visto, permite que o olho geométrico realize inferências quanto ao tamanho, à figura e ao movimento daquilo que ele vê.

Se o tamanho daquilo que se vê não pode ser determinado pela distância em que se encontra do olho, mas somente pela magnitude da abertura do ângulo visual, como nos ensina o oitavo teorema, então de que modo se percebe a própria distância? Acerca disso, o tratado de Euclides nada afirma explicitamente. Na terceira proposição de sua Óptica, em que se afirma que "tudo aquilo que é visto tem uma distância longitudinal que, quando alcançada, não é mais visto", e também em sua nona proposição, em que se ataca o problema da aparente "torre redonda", tem-se a existência de um limite de visibilidade relacionado à distância. Todavia, de que maneira a própria distância é percebida ou estimada? Na Óptica de Ptolomeu, a percepção da distância é função da própria extensão (ou comprimento) do "raio visual", como diz A. Mark Smith, "cada raio [visual] é dotado de uma capacidade de sentir sua própria extensão" (Smith, 1996, p. 24). Não parece que Euclides discordaria dessa concepção.

Quanto à percepção da figura, Euclides dedica um grupo de teoremas (proposições 22-36) concernente à percepção de certos objetos geométricos, em que estuda a aparência da esfera (proposições 23-27), do cilindro (proposições 28-29), do cone (proposições 3o-33) e do círculo (proposições 22 e 34-36). No caso da percepção da esfera, suas regiões visíveis variam de acordo com sua posição em relação ao olho. Assim, dependendo da relação entre o ângulo visual e a esfera, e também de se a esfera é vista com apenas um olho ou se é vista com os dois olhos, ${ }^{20}$ "a parte vista da esfera"

20 As proposições 25-27 são as únicas passagens da Óptica em que se faz referência aos “dois olhos”. Todavia, não se trata de uma consideração acerca da visão binocular, ou do problema da fusão de imagens (o que será posteriormente enfrentado por Ptolomeu), mas apenas leva em conta a distância linear entre os dois olhos. Como demonstra a proposição 26, se essa distância for maior do que o diâmetro de uma esfera, então mais do que um hemisfério será visto. Essa é a única possibilidade de os raios visuais capturarem mais do que um hemisfério - aplica-se somente a esferas pequenas, cujos diâmetros sejam menores do que a distância entre os dois olhos. 
será maior, menor ou igual a um hemisfério dessa esfera. No caso do cilindro e do cone, o raciocínio é semelhante, a aparência que o feixe de raios visuais produzirá também depende das relações angulares entre o olho e o objeto geométrico. Quanto ao círculo, sua aparência também depende da posição relativa que mantém com o olho, variando o aspecto de seus diâmetros de acordo com a situação do olho frente ao círculo. Euclides determina o "lugar geométrico" (uma linha reta) em que o olho deve ser posto para que os diâmetros do círculo apareçam iguais (caso em que o círculo tem, pois, a aparência de círculo, na proposição 34) e também o lugar a partir do qual os diâmetros do círculo são vistos desiguais (caso em que o círculo não se mostra, pois, com aparência circular, mas oblonga, na proposição 35) - a proposição 36 parece funcionar como um corolário de perspectiva ao enunciar: "as rodas dos carros aparecem algumas vezes circulares e algumas vezes oblongas".

No que concerne à percepção do movimento, Euclides dedica as proposições 50 a 56, nas quais estuda certas "ilusões visuais" que são produzidas pelo deslocamento relativo entre "magnitudes movidas" e o olho. Assim, se três magnitudes, diferentemente distantes em relação ao olho, deslocam-se com a mesma velocidade sobre uma linha reta perpendicular ao olho e em direção ao eixo visual, então a magnitude mais afastada "parecerá" que se desloca mais rapidamente do que as outras, enquanto a mais próxima "parecerá” que percorre mais lentamente; e quando as três magnitudes ultrapassam o eixo visual, então a situação se inverte e é a magnitude mais afastada aquela que "parecerá" deslocar-se mais lentamente do que as outras (proposição 50).

Na proposição 51, na qual o deslocamento do olho é introduzido na situação, encontra-se o primeiro registro de um princípio de relatividade óptica do movimento (cf. Eecke, 1959, p. xxiii e p. 47, nota 1; Simon, 1988, p. 75). Assim, quando o olho se desloca paralelamente e com a mesma "rapidez" que a magnitude visível, então esta parecerá imóvel, enquanto que a magnitude que segue mais lentamente a mesma trajetória parecerá recuar, isto é, parecerá que é “movida na direção contrária”, e, enfim, aquela que segue mais rapidamente que o olho "parecerá” avançar. Portanto, a percepção do movimento e do repouso é relativa ao movimento, ou repouso, do próprio olho.

\section{Consideração FinAL}

Como se pode ver, Euclides elabora uma "geometria do visível" que se constitui como uma ciência da aparição dos chamados "sensíveis comuns", ou daquelas características geométrico-cinéticas que podem ser apreendidas pela sensação das "magnitudes visíveis". Contudo, sua análise geométrica da visão é fundamentalmente orientada pela ideia fundamental de uma extromissão de "raios visuais", uma suposição de física 
(extrageométrica) que irradia seu valor de verdade para todo o sistema. Assim, uma vez que o núcleo da teoria euclidiana da visão não é verdadeiro, ou que suas suposições ou premissas fundamentais são materialmente falsas, segue-se, necessariamente, que suas "demonstrações" não podem estabelecer proposições verdadeiras. Como sabemos, a suposição extramissionista da óptica antiga tornou-se "falsa" depois que Kepler, completando a revolução da ciência da óptica iniciada no século xir por Alhazen, decifrou o mecanismo da visão - esta se faz pela intromissão da luz no interior do olho. Todavia, como dizia Gérard Simon, antes que uma "ciência falsa", a óptica de Euclides deveria ser tomada como uma "ciência fóssil" (cf. Simon, 1988, p. 199; 2003, p. 18).

Agradecimentos. Este trabalho contou com o apoio da Fundação de Amparo à Pesquisa do Estado de São Paulo, como parte do projeto de pesquisa de pós-doutorado (Projeto 2011/21629-9). Agradeço aos professores Marco Zingano (DF-USP), Marisa Carneiro de Oliveira Franco Donatelli (DF-UESC) e Pablo Rubén Mariconda (DF-USP) pelas relevantes críticas e valiosas sugestões.

\section{Guilherme Rodrigues Neto \\ Departamento de Filosofia,}

Faculdade de Filosofia, Letras e Ciências Humanas, Universidade de São Paulo, Brasil. guirneto@usp.br

\section{Euclid and the geometry of the visual ray}

This introductory essay provides an abridged presentation of the optical treatise attributed to Euclid of Alexandria, placing it in the context of theories about vision formulated by the ancient philosophical doctrines. I emphasize the antagonism between the geometric analysis of vision, undertaken by Euclid, and the philosophical considerations about the physical processes underlying visual sensation. In addition, I aim to show that the object of Euclidean optics is the visual perception of what Aristotle calls "common sensible". 
Euglides e A geometria do RAio Visual

\section{REFERÊNGIAS BIBLIOGRÁFIGAS}

Aristóteles. Posterior analytics. In: Barnes, J. (Ed.). The complete works of Aristotle. The revised Oxford translation. Princeton/New Jersey: Princeton University Press, 1984. v. 1, p. 114-166. (An. Post.)

.Physics. In: Barnes, J. (Ed.). The complete works of Aristotle. The revised Oxford translation. Princeton/

New Jersey: Princeton University Press, 1984. v. 1, p. 315-446. (Física)

.De caelo. In: BARnes, J. (Ed.). The complete works of Aristotle. The revised Oxford translation. Princeton/

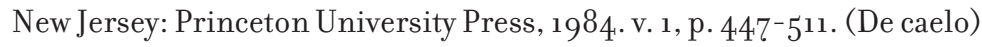

. Meteorology. In: Barnes, J. (Ed.). The complete works of Aristotle. The revised Oxford translation.

Princeton/New Jersey: Princeton University Press, 1984. v. 1, p. 555-625. (Metereologica)

. On the soul. In: Barnes, J. (Ed.). The complete works of Aristotle. The revised Oxford translation. Princeton/

New Jersey: Princeton University Press, 1984. v. 1, p. 641-92. (De anima)

. Sense and sensibilia. In: Barnes, J. (Ed.). The complete works of Aristotle. The revised Oxford translation.

Princeton/New Jersey: Princeton University Press, 1984. v. 1, p. 693-713. (De sensu)

. On dreams. In: BARnes, J. (Ed.). The complete works of Aristotle. The revised Oxford translation. Princeton/

New Jersey: Princeton University Press, 1984. v. 1, p. 729-735. (De Somn.)

. Metaphysics. In: Barnes, J. (Ed.). The complete works of Aristotle. The revised Oxford translation.

Princeton/New Jersey: Princeton University Press, 1984. v. 2, p. 1552-1728. (Metafísica)

Baldes, R. W. Democritus on visual perception: two theories or one? Phronesis, 20, 2, p. 93-105, 1975.

Barnes, J. (Ed.). The complete works of Aristotle. The revised Oxford translation. Princeton/New Jersey:

Princeton University Press, 1984. 2 v.

Beare, J. I. Greek theories of elementary cognition from Alcmeon to Aristotle. Oxford: Clarendon Press, 1906.

Berryman, S. Euclid and the sceptic: a paper on vision, doubt, geometry, light and drunkenness. Phronesis,

43,2, p. $176-96,1998$.

BLock, I. Truth and error in Aristotle's theory of sense perception. The Philosophical Quarterly, 11, 4, p. 1$19,1961$.

Burkert, W. Air-imprints or eidole. Democritus' aetiology of vision. Illinois Class.Studies, 2, p. 79-109, 1977 .

Burnyeat, M. F. De anima II 5. Phronesis, 47, 1, p. 28-90, 2002.

Burton, H. E. Euclid's optics. Journal of the Optical Society, 35, 5, p. 357-72, 1945.

Cooper, J. M. \& Hutchinson, D. S. (Ed.). Plato: complete works. Indianapolis: Hackett Publishing, 1997.

Darrigol, O. A history of optics. From greek antiquity to the nineteenth century. Oxford: Oxford University Press, 2012.

Des Chene, D. Life's form: late aristotelian conceptions of the soul. Ithaca: Cornell University Press, 2000.

Eecke, P. V. Euclide: l'optique et la catoptrique. Paris: Albert Blanchard, 1959.

Euclides. Os elementos. Tradução I. Bicudo. São Paulo: Unesp, 2009.

Furley, D. J. The greek cosmologists. Cambridge: Cambridge University Press, 1987.

Gaukroger, S. Aristotle on the function of sense perception. Studies in History and Philosophy of Science, 12,1, p. $75^{-89}, 1981$.

Hamlyn, D. W. Aristotle's account of aesthesis in the "De anima". The Classical Quarterly, 9, 1, p. 1-16, 1959.

Heath, T. L. A history of greek mathematics. New York: Dover, 1981. 2 v.

Heiberg, I. L. (Ed.). Euclidis opera omnia. Lipsiae: Teubneri, 1895 v. 7 .

KrIPs, H. Aristotle on the infallibility of normal observation. Studies in History and Philosophy of Science, 11, 1, p. 79-86, 1980. 
Knuuttila, S. \& Kärkkäinen, P. (Ed.). Theories of perception in medieval and early modern philosophy. Dordrecht: Springer, 2008. (Studies in the History of Philosophy of Mind 6)

Laertius, D. Lives of eminent philosophers. Tradução R. D. Hicks. Harvard: Harvard University Press, 1925. $2 \mathrm{v}$.

Lindberg, D. G. Theories of vision from al-Kindi to Kepler. Chicago/London: University of Chicago Press, 1976.

LøкKE, H. The stoics on sense perception. In: KnuUtTıla, S. \& KärkKÄInen, P. (Ed.). Theories of perception in medieval and early modern philosophy. Dordrecht: Springer, 2008. p. 35-46.

Panofsky, E. A perspectiva como forma simbólica. Lisboa: Edições 7०, 1993 [1927].

Platão. Theaetetus. In: Cooper, J. M. \& Hutchinson, D. S. (Ed.). Plato: complete works. Indianapolis: Hackett Publishing, 1997·p. 157-234. (Teeteto)

. Republic. In: Cooper, J. M. \& Hutchinson, D. S. (Ed.). Plato: complete works. Indianapolis: Hackett

Publishing, 1997. p. 971-1223. (República)

Timaeus. In: Cooper, J. M. \& Hutchinson, D. S. (Ed.). Plato: complete works. Indianapolis: Hackett Publishing, 1997. p. 1224-1291. (Timeu)

Polansky, R. Aristotle's De anima. Cambridge: Cambridge University Press, 2007.

Rudolph, K. Democritus' perspectival theory of vision. Journal of Hellenic Studies, 131, p. 67-83, 2011.

Sextus Empiricus. Outlines of pyrrhonism. Harvard: Harvard University Press, 1976. (HP)

SiEgeL, R. E. Did the greek atomist consider a non-corpuscular visual transmission? Reconsideration of some ancient visual doctrines. Archives Internationales d'Historie des Sciences, 22, p. 3-16, 1969.

Simon, G. Le regard, l'être et l'apparence dans l'optique de l'Antiquité. Paris: Seuil, 1988.

.Aux origines de la théorie des miroirs: sur l'authenticité de la "Catoptrique" d'Euclide. Revue d'Histoire des Sciences, 47, 2, p. 259-72, 1994 .

. Archéologie de la vision. L'optique, le corps, la peinture. Paris: Seuil, 2003.

Sмiтн, A. M. Ptolemy's theory of visual perception: an english translation of the "Optics" with introduction and commentary. Transactions of the American Philosophical Society, 86, 2, 1996.

Sorabj, R. Aristotle on demarcating the five senses. The Philosophical Review, 80, 1, p. 55-79, 1971.

Body and soul in Aristotle. Philosophy, 49, 187, p. 63-89, 1974.

Theisen, W. R. Liber de visu: the greco-latin translation of Euclid's Optics. Medieval Studies, 41, p. 44-105, 1979 .

Tовіn, R. Ancient perspective and Euclid's optics. Journal of the Warburg and Courtauld Institutes, $5^{3}$, p. $14,41,1990$.

Tossato, G. R. A função do olho humano na óptica do final do século xvi. Scientiae Studia, 3, 3, p. 4115-411, 2005 .

Zingano, M. Razão e sensação em Aristóteles: um ensaio sobre De anima III 4-5. Porto Alegre: L\&PM, 1998.

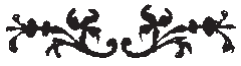

